\title{
Synthesis of Photocrosslinkable Hyperbranched Polysulfide Containing Methacryloyl Groups by the Reaction of Bis(oxetane) with Thiocyanuric Acid Followed by the Reaction with Methacrylic Anhydride
}

\author{
By Ken MARUYAMA, Naoyuki KoIKE, Hiroki SUGIMoto, Hiroto KUDO, and Tadatomi NISHIKUBO*
}

\begin{abstract}
The synthesis and photopolymerization of hyperbranched polysulfides containing pendant methacryloyl groups (HBPS-MA) were examined. Polyadditions of 1,4-bis[(3-ethy-3-oxetanyl)methoxy]benzene (1,4-BEOMB) with thiocyanuric acid (TCA) were carried out to give the soluble hyperbranched polysulfides (HBPS) in satisfactory high yields. Then, we examined refractive index of the resulting HBPS. Furthermore, HBPS-MA was synthesized by the reaction of HBPS with methacrylic anhydride. The photo-initiated radical polymerization of HBPS-MA was performed in the presence of 2-methyl-1-[4(methylthio)phenyl]-2-morpholinopropan-2-one (Irgacure $907^{\circledR}$ ) as a photoinitiator in the film state upon UV irradiation to afford the insoluble cured film.

KEY WORDS: Hyperbranched Poly(sulfide) / Photoradical Polymerization / Refractive Index / Oxetane /
\end{abstract}

UV curing system has great interest as advanced technology from the view points of environmental protection, energy saving, and high productivities which have been used mainly for coating, printing inks, and adhesives for more than 35 years. $^{1,2}$ Recently, application fields of UV curing materials grew with the advancement of electronics and information industries due to their excellent performance. Furthermore, new functionalities such as low birefringence and high-/lowrefractive index have been required for their progress in new fields such as optical device and optical memory.

Dendritic polymers such as dendrimers and hyperbranched polymers possess branched structures and have recently attracted a great deal of attention for their unique properties such as lower viscosity, ${ }^{3,4}$ good solubility, ${ }^{5}$ and many reactive terminal groups compared with the corresponding linear ones. Therefore, dendritic polymers containing a large number of terminal (meth)acryloyl groups have great possibility as a new high performance UV curing system. Ranby and Shi reported ${ }^{6}$ on the synthesis of dendritic polyesters containing terminal (meth)acryloyl groups. Furthermore, they found that photocured film of dendritic polyester containing (meth)acryloyl groups have high glass transition temperatures. However, these dendritic polymers were synthesized by multi-step reactions.

On the other hand, hyperbranched polymers (HBPs) are prepared by the two methods in general. One is polymerization of $\mathrm{AB}_{2}$ monomers, ${ }^{7,8}$ and another is polymerization of $\mathrm{A}_{2}$-type monomers with $\mathrm{B}_{3}$-type monomers. ${ }^{9,10}$ The latter method is suitable for a large scale production, because commercial compound can be used as monomer, although control of polymerization is required in order to avoid gel production.

Recently, we examined ${ }^{11,12}$ the synthesis, the photo-chemical reaction and other properties of photo-curable HBPs. Then it was found that birefringence of the cured HBPs was lower than that of linear ones as an interesting result. This result shows that photo-curable HBPs are new type of UV curing materials for new application field such as optical device and optical memory.

Meanwhile, the synthesis and properties of the polymer containing sulfur atoms have been of interest for the development of high refractive index materials. Ueda and his coworker reported ${ }^{13-15}$ on the synthesis of aromatic polyimide containing sulfur atom. They also investigated thermal and optical properties of the aromatic polyimide containing sulfur atom, and found that obtained polyimide have high thermal stability, high transparency, and low birefringence. Nishikubo et al. reported ${ }^{16}$ on the syntheses and refractive index properties of new octa-arm star-shaped polymers containing sulfur atom, and they found that the resulting star-shaped polymers have higher refractive index values compared to those of corresponding linear polymers.

In this article, we examined the synthesis and refractive index properties of hyperbranched polysulfide. We also performed the synthesis and photo-induced radical polymerization of hyperbranched polysulfide containing pendant methacryloyl groups.

\section{EXPERIMENTAL}

\section{Materials}

The reaction solvents, such as 1,4-dioxane, o-dichlorobenzene, dimethylformamide (DMF), dimethylacetamide (DMAc), $N$-methylpyrrolidone (NMP), and dimethyl sulfoxide (DMSO) were dried with $\mathrm{CaH}_{2}$, and purified by distillation before use. Tetraphenylphosphonium bromide (ТРPB) was dried in vacuo, 
and used without further purification. Commercial thiocyanuric acid (TCA), methacrylic anhydride (MAAH), 2-hydroxyethyl methacrylate (HEMA), 2-methyl-1-[4-(methylthio)phenyl]-2morpholinopropan-2-one (Irgacure $907^{\circledR}$, Ciba Japan K.K.), hydroquinone (HQ), and triethylamine (TEA) were used without further purification. 1,4-Bis[(3-ethy-3-oxetanyl)methoxy]benzene (1,4-BEOMB) was donated from Toagosei Co., Ltd., and was purified by recrystallization from appropriate solvents.

\section{Measurement}

Infrared (IR) absorption spectra were measured on a Jasco FT/IR-420 spectrometer. The ${ }^{1} \mathrm{H}$ NMR spectrum was recorded on a JEOL model JNM $\alpha-600\left(600 \mathrm{MHz}\right.$ for ${ }^{1} \mathrm{H}$ NMR) in DMSO- $d_{6}$. The number-average molecular weight $\left(M_{\mathrm{n}}\right)$ and molecular weight distribution $\left(M_{\mathrm{w}} / M_{\mathrm{n}}\right)$ of the polymers were estimated by size exclusion chromatography (SEC) with the use of a TOSOH HLC-8220 SEC equipped with refractive index and ultraviolet detectors using TSK gel columns [eluent: solution of $\mathrm{LiBr}$ and phosphoric acid $(20 \mathrm{mM})$ in $\mathrm{DMF}]$; calibrated with narrow molecular weight polystyrene standards. Real-time Infrared (RT-IR) absorption spectra were recorded on a BIO-RAD Excalibur FTS-3000MX spectrometer equipped with a HOYA-SCHOTT EX250 UV light source. The refractive-index of the polymers spin-coated on silicon wafers was measured by ellipsometry at $0.6328 \mu \mathrm{m}$ with a Gaertener Scientific. Co. model L116C ellipsometer.

\section{Synthesis of Hyperbranched Polysulfide (HBPS) by Polyad-} dition of 1,4-BEOMB with TCA

A typical procedure for the polyaddition of 1,4-BEOMB with TCA is as follows: The mixture of 1,4-BEOMB $(0.460 \mathrm{~g}$; $1.5 \mathrm{mmol})$, TMA $(0.177 \mathrm{~g} ; 1.0 \mathrm{mmol})$, and TPPB $(0.031 \mathrm{~g}$; $0.075 \mathrm{mmol})$ in NMP $(1.25 \mathrm{~mL})$ was stirred at $130{ }^{\circ} \mathrm{C}$ for $4 \mathrm{~h}$. The resulting mixture was poured into a large amount of water to precipitate the polymer. The resulting polymer was reprecipitated twice from THF into methanol, and dried in vacuo at r.t. for $24 \mathrm{~h}$. The yield of HBPS was $0.392 \mathrm{~g}(62 \%)$. $M_{\mathrm{n}}$ of HBPS estimated by SEC was $6900\left(M_{\mathrm{w}} / M_{\mathrm{n}}=4.6\right)$. IR (film, $\left.\mathrm{cm}^{-1}\right): 3420\left(v_{\mathrm{O}-\mathrm{H}}\right), 1508\left(v_{\mathrm{C}=\mathrm{C}}\right.$ of aromatic), 985 ( $v_{\mathrm{C}-\mathrm{O}-\mathrm{C}}$, cyclic ether). ${ }^{1} \mathrm{H}$ NMR $\left(600 \mathrm{MHz}, \mathrm{DMSO}-d_{6}, \delta, \mathrm{ppm}\right)$ : 0.58-1.02 (m, 6.1 H, $\left.\mathrm{CH}_{2} \mathrm{CH}_{3}\right), 1.12-1.90(\mathrm{~m}, 4.0 \mathrm{H}$, $\left.-\mathrm{CH}_{2} \mathrm{CH}_{3}\right), 1.90-2.31(\mathrm{~m}, 0.9 \mathrm{H},-\mathrm{S} \underline{\mathrm{H}}), 2.52-2.80(\mathrm{~m}, 0.6 \mathrm{H}$, $-\mathrm{OH}) 3.50-5.05$ (m, $12.0 \mathrm{H}, \mathrm{C}-\mathrm{CH}_{2}-\mathrm{O}, \mathrm{CH}_{2}-\mathrm{OH}, \mathrm{C}-\mathrm{CH}_{2}-\mathrm{S}$, and $\mathrm{C}-\mathrm{C}_{2}-\mathrm{O}$ in oxetane ring), 6.32-7.34 (m, $4.0 \mathrm{H}$, aromatic $\mathrm{H}$ ).

\section{Synthesis of Hyperbranched Polysulfide Containing Meth- acryloyl Groups (HBPS-MA)}

The mixture of HBPS $\left(0.95 \mathrm{~g}, M_{\mathrm{n}}=4400, M_{\mathrm{w}} / M_{\mathrm{n}}=1.4\right)$, MAAH (2.19g, $14 \mathrm{mmol})$, TEA $(1.39 \mathrm{~g}, 14 \mathrm{mmol})$, and small amount of HQ in THF $(16 \mathrm{~mL})$ was stirred at $25^{\circ} \mathrm{C}$ for $24 \mathrm{~h}$. The resulting mixture was poured into a large amount of water to precipitate the polymer. The resulting polymer (HBPS-MA) was reprecipitated twice from THF into diethyl ether, and dried in vacuo at r.t. for $24 \mathrm{~h}$. The yield of HBPS-MA was $0.82 \mathrm{~g}$ (85\%). IR (film, $\left.\mathrm{cm}^{-1}\right): 1720 \quad\left(v_{\mathrm{C}=\mathrm{O}}\right.$ ester), $1636 \quad\left(v_{\mathrm{C}=\mathrm{C}}\right.$ methacryl), 1226, 1054 ( $v_{\mathrm{C}-\mathrm{O}-\mathrm{C}}$ ester). ${ }^{1} \mathrm{H}$ NMR $(600 \mathrm{MHz}$, DMSO- $d_{6}, \delta, \quad$ ppm): $0.58-1.85\left(\mathrm{~m}, 10.0 \mathrm{H}, \quad \mathrm{CH}_{2} \mathrm{CH}_{3}\right.$, $\left.-\mathrm{CH}_{2} \mathrm{CH}_{3}\right), 1.85-2.21\left(\mathrm{~m}, 4.5 \mathrm{H}, \mathrm{C}\left(\mathrm{CH}_{3}\right)=\mathrm{CH}_{2}\right), 3.50-5.05$ (m, $12.0 \mathrm{H}, \mathrm{C}-\underline{\mathrm{C}}_{2}-\mathrm{O}, \mathrm{C}_{2}-\mathrm{OH}, \mathrm{C}-\underline{\mathrm{C}}_{2}-\mathrm{S}$, and $\mathrm{C}-\underline{\mathrm{CH}}_{2}-\mathrm{O}$ in oxetane ring), 5.53-5.93 (m, 3.0 H, C $\left.\left(\mathrm{CH}_{3}\right)=\mathrm{CH}_{2}\right), 6.32-7.34$ (m, 4.0 H, aromatic $\mathrm{H})$.

\section{Photo-Initiated Radical Polymerization}

The photo-initiated radical polymerization of HBPS-MA was performed in the film state as follows. HBPS-MA (97 wt \%) and Irgacure $907^{\circledR}(3 \mathrm{wt} \%)$ as a photo-initiator were dissolved in THF and dried to make film on the $\mathrm{KBr}$ plate. The film, containing a photo-initiator on the plate, was irradiated with a $250-\mathrm{W}$ high-pressure mercury lamp (HOYA-SCHOTT Co.) without a filter under air. The intensity of the light was kept at $8 \mathrm{~mW} / \mathrm{cm}^{2}$ (at $254 \mathrm{~nm}$ ). The rate of decrease in the $\mathrm{C}=\mathrm{C}$ stretching near $1636 \mathrm{~cm}^{-1}$ due to methacryloyl group in HBPS-MA was measured by RT-IR.

\section{RESULTS AND DISCUSSION}

\section{Synthesis of Hyperbranched Polysulfide (HBPS)}

We examined the effect of time on the polyaddition of 1,4BEOMB with TCA at $130{ }^{\circ} \mathrm{C}$ in NMP using $5 \mathrm{~mol} \%$ of TPPB as a catalyst (Scheme 1). As summarized in Table I, total yields (yield of soluble parts in THF + yield of insoluble parts in THF) of the resulting polymers increased with time. However, on the reaction at $5 \mathrm{~h}$, insoluble parts in THF (gel products) appeared and gel product increased with time. This means that $4 \mathrm{~h}$ is a suitable reaction time to obtain only a soluble polymer under this reaction condition.

The structure of the resulting polysulfide on the reaction at $4 \mathrm{~h}\left(M_{\mathrm{n}}=6900\right.$ and $\left.M_{\mathrm{w}} / M_{\mathrm{n}}=4.6\right)$ was confirmed by IR and ${ }^{1} \mathrm{H}$ NMR spectroscopy. The IR spectrum showed characteristic absorption peaks at 3420 and $985 \mathrm{~cm}^{-1}$ assignable to the $-\mathrm{O}-\mathrm{H}$ and $\mathrm{C}-\mathrm{O}-\mathrm{C}$ (cyclic ether), respectively. As shown in Figure 1, the ${ }^{1} \mathrm{H}$ NMR spectrum of this polymer showed proton signals due to thiol groups $\left(\mathrm{H}^{\mathrm{l}}\right)$ of the ends of the polymer chains at $1.90-2.31 \mathrm{ppm}$, hydroxyl groups $\left(\mathrm{H}^{\mathrm{k}}\right)$ of pendant polymer chains at $2.52-2.80 \mathrm{ppm}$, and oxetanyl groups $\left(\mathrm{H}^{\mathrm{c}}\right)$ of the end of polymer chain at $4.20-4.55 \mathrm{ppm}$. This result suggested that HBPS with thiol groups and oxetanyl groups at the end of polymer chain was prepared.
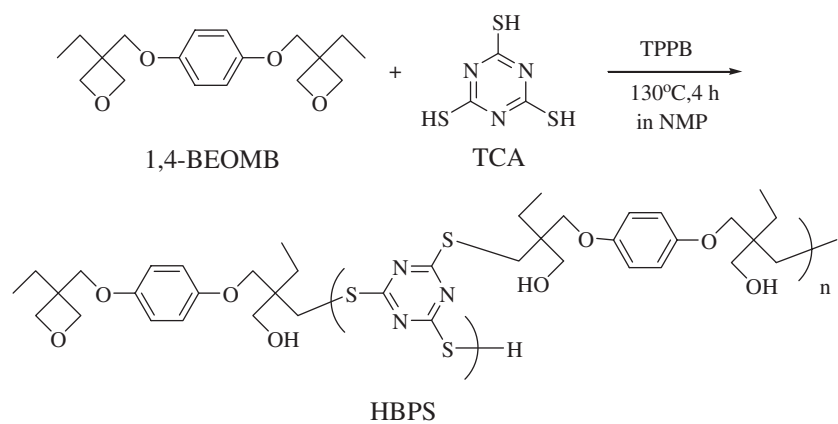

Scheme 1. 
Table I. Effect of reaction time on the polyaddition of 1,4-BEOMB with $\mathrm{TCA}^{\mathrm{a}}$

\begin{tabular}{ccllr}
\hline Run & Reaction time $(\mathrm{h})$ & Yield $(\%)$ & $M_{\mathrm{n}}^{\mathrm{b}, \mathrm{c}}$ & $M_{\mathrm{w}} / M_{\mathrm{n}}^{\mathrm{b}, \mathrm{c}}$ \\
\hline 1 & 3 & $33^{\mathrm{b}}$ & 3700 & 2.2 \\
2 & 4 & $62^{\mathrm{b}}$ & 6900 & 4.6 \\
3 & 5 & $72^{\mathrm{b}}(5)^{\mathrm{d}}$ & 9600 & 49.3 \\
4 & 6 & $14^{\mathrm{b}}(71)^{\mathrm{d}}$ & 6400 & 2.7 \\
\hline
\end{tabular}

a The reaction was carried out with 1 4-BEOMB $(1.5 \mathrm{mmol})$ and TCA $(1.0 \mathrm{mmol})$ using $5 \mathrm{~mol} \%$ of TPPB in NMP $(1.25 \mathrm{~mL})$ at $130^{\circ} \mathrm{C}$ for various times. ${ }^{b}$ Soluble parts in THF. ' Estimated by SEC based on polystyrene standards. ${ }^{\mathrm{d}}$ Insoluble parts in THF.
Table II. Effect of solvent on the polyaddition of 1,4-BEOBM with TCA ${ }^{a}$

\begin{tabular}{ccccc}
\hline Run & Solvent & Yield $(\%)^{\mathrm{b}}$ & $M_{\mathrm{n}}^{\mathrm{b}, \mathrm{c}}$ & $M_{\mathrm{w}} / M_{\mathrm{n}}^{\mathrm{b}, \mathrm{c}}$ \\
\hline 1 & Dioxane & 0 & - & - \\
2 & o-dichlrobenzen & 0 & - & - \\
3 & DMF & 48 & 3600 & 2.6 \\
4 & DMAc & 64 & 4400 & 3.7 \\
5 & NMP & 62 & 6900 & 4.6 \\
\hline
\end{tabular}

a The reaction was carried out with 1,4-BEOMB $(1.5 \mathrm{mmol})$ and TCA $(1.0 \mathrm{mmol})$ using $5 \mathrm{~mol} \%$ of TPPB in various solvent $(1.25 \mathrm{~mL})$ at $130^{\circ} \mathrm{C}$ for $4 \mathrm{~h}$. ${ }^{\mathrm{b}}$ Soluble parts in THF. ${ }^{\mathrm{C}}$ Estimated by SEC based on polystyrene standards.
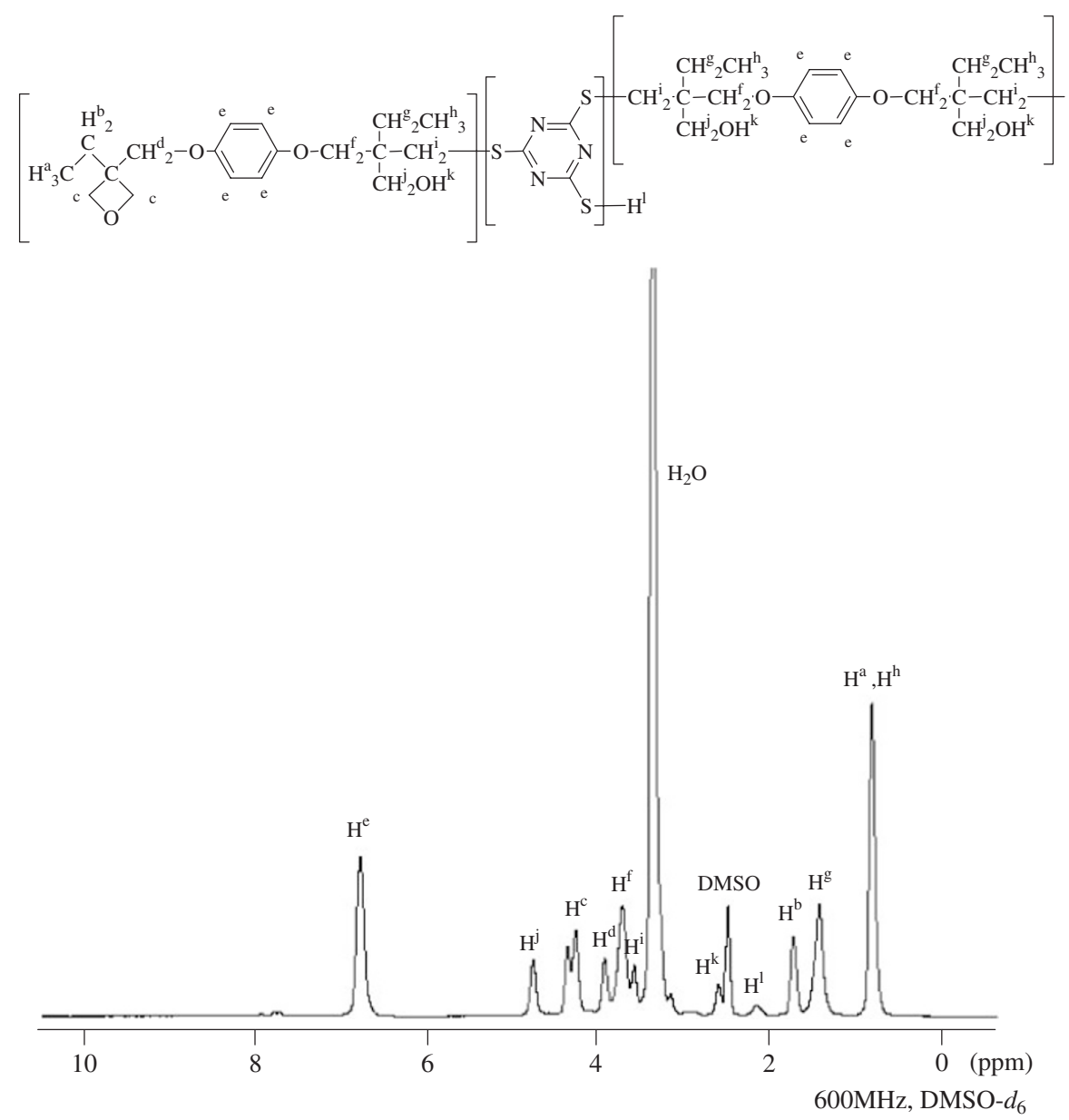

Figure 1. ${ }^{1} \mathrm{H}$ NMR spectrum of hyperbranched polysulfide.

The effect of reaction medium was examined at $4 \mathrm{~h}$ under the same conditions based on the results of Table I. As summarized in Table II, the polyaddition of 1,4-BEOBM with TCA proceeded in DMF, DMAc, and NMP to give the soluble polymers (Table II). No reaction occurred in 1,4-dioxane and $o$-dichlorobenzene, because TCA was insoluble in these solvent under this reaction condition.

This means that NMP is a suitable reaction solvent for the polyaddition of 1,4-BEOBM with TCA to afford corresponding hyperbranched polysulfide containing many pendant hydroxyl groups.
We also examined the effect of reaction temperature using $5 \mathrm{~mol} \%$ of TPPB as a catalyst in NMP. As shown in Table III, although no reaction occurred at $110^{\circ} \mathrm{C}$ for $4 \mathrm{~h}$, the yields and $M_{\mathrm{n}} \mathrm{s}$ of hyperbranched polymers increased gradually with temperatures at $120-130^{\circ} \mathrm{C}$. However, when the polyaddition was performed at $140{ }^{\circ} \mathrm{C}$ for $4 \mathrm{~h}, 81 \mathrm{wt}-\%$ of gel products and $3 \mathrm{wt}-\%$ of soluble products were obtained. Therefore, it seems that $130{ }^{\circ} \mathrm{C}$ was suitable reaction temperature to obtain soluble hyperbranched polymer in good yields.

The effect of feed ratio of TCA was also examined at $130^{\circ} \mathrm{C}$ for $4 \mathrm{~h}$ in NMP using 5 mol- $\%$ of TPPB as the catalyst. As 
Table III. Effect of reaction temperature on the polyaddition of 1,4-BEOBM with TCA

\begin{tabular}{ccccc}
\hline Run & Reaction temperature $\left({ }^{\circ} \mathrm{C}\right)$ & Yield $(\%)$ & $M_{\mathrm{n}}^{\mathrm{b}, \mathrm{c}}$ & $M_{\mathrm{w}} / M_{\mathrm{n}}^{\mathrm{b}, \mathrm{c}}$ \\
\hline 1 & 110 & $0^{\mathrm{b}}$ & - & - \\
2 & 120 & $24^{\mathrm{b}}$ & 3600 & 1.8 \\
3 & 130 & $62^{\mathrm{b}}$ & 6900 & 4.6 \\
4 & 140 & $3^{\mathrm{b}}(81)^{\mathrm{d}}$ & 9800 & 5.0 \\
\hline
\end{tabular}

a The reaction was carried out with 1,4-BEOMB $(1.5 \mathrm{mmol})$ and TCA $(1.0 \mathrm{mmol})$ using $5 \mathrm{~mol} \%$ of TPPB in NMP $(1.25 \mathrm{~mL})$ at various temperature for $4 \mathrm{~h}$. ${ }^{\mathrm{b}}$ Soluble parts in THF. ${ }^{\mathrm{c}}$ Estimated by SEC based on polystyrene standards. ${ }^{\mathrm{d}}$ Insoluble parts in THF.
Table IV. Effect of feed ratio of TCA on the polyaddition of 1,4-BEOBM with TCA ${ }^{\mathrm{a}}$

\begin{tabular}{cccccc}
\hline Run & Feed ratio (mmol) & Yield (\%) & $M_{\mathrm{n}}^{\mathrm{b}, \mathrm{c}}$ & $M_{\mathrm{w}} / M_{\mathrm{n}}{ }^{\mathrm{b}, \mathrm{c}}$ & Refractive index $^{\mathrm{b}, \mathrm{d}}$ \\
\cline { 2 - 5 } & 1,4-BEOMB/TCA & & & & \\
\hline 1 & $1.5 / 0.6$ & 10 & 4400 & 1.4 & 1.600 \\
2 & $1.5 / 0.7$ & 26 & 4200 & 1.7 & 1.599 \\
3 & $1.5 / 0.8$ & 33 & 4500 & 1.8 & 1.598 \\
4 & $1.5 / 0.9$ & 55 & 6200 & 3.6 & 1.598 \\
5 & $1.5 / 1$ & 62 & 6900 & 4.6 & 1.594 \\
\hline
\end{tabular}

aThe reaction was carried out with 1,4-BEOMB $(1.5 \mathrm{mmol})$ and TCA $(1.0 \mathrm{mmol})$ using $5 \mathrm{~mol} \%$ of TPPB in NMP $(1.25 \mathrm{~mL})$ at $130^{\circ} \mathrm{C}$ for $4 \mathrm{~h}$. bSoluble parts in THF. ' Estimated by SEC based on polystyrene standards. ${ }^{d}$ Average values of refractive indices determined by ellipsometer using $0.6328 \mu \mathrm{m}$.<smiles>C=C(C)C(=O)OCC(CC)(COc1ccc(OCC(CC)(COC(=O)C(=C)C(=O)OC(=O)C(=C)C)COC(=O)C(C)(C)C)cc1)COc1ccc(OCC(CC)(CO)CC(C)(C)C)cc1</smiles>

HBPS-MA

Scheme 2

summarized in Table IV, hyperbranched polymer with the highest molecular weight was obtained, when the feed ratios of $1,4-\mathrm{BEOBM} / \mathrm{TCA}=1.5 / 1$, and it was found that the molecular weights decreased with decreasing feed ratio of TCA.

The refractive index of resulting polymer was also estimated. These results are summarized in Table IV. The refractive indices of the obtained polymer were gradually decreased from 1.600 to 1.594 with increasing feed ratio of TCA. According to the Lorentz-Lorenz equation, the introduction of substituent with low molar refractions and increasing molar volume can efficiently decrease the refractive indices. From this result, it is expected that molar volume of polymer is increasing by increasing branch unit (increasing feed ratio of TCA).

\section{Synthesis of Hyperbranched Polysulfide with Methacryloyl Groups (HBPS-MA)}

The introduction of the methacryloyl groups into HBPS was performed (Scheme 2). The reaction of HBPS $\left(M_{\mathrm{n}}=4400\right.$, $\left.M_{\mathrm{w}} / M_{\mathrm{n}}=1.4\right)$ with MAAH was carried out using TEA at $25^{\circ} \mathrm{C}$ for $24 \mathrm{~h}$, and it was found that the corresponding hyperbranched polysulfide containing $>99 \%$ of the pendant methacryloyl groups (HBPS-MA) was obtained in $85 \%$ yield. The degree of conversion of hydroxyl groups was $>99 \%$, which was confirmed by IR spectroscopy.
The structure of HBPS-MA was confirmed by ${ }^{1} \mathrm{H}$ NMR and IR spectroscopy. The IR spectrum showed characteristic absorption peaks at 1719 and $1636 \mathrm{~cm}^{-1}$ assignable to the $\mathrm{C}=\mathrm{O}$ and $\mathrm{C}=\mathrm{C}$ (metacryloyl), respectively (Figure 2). Furthermore, characteristics absorption peak of $3420 \mathrm{~cm}^{-1}$ assignable to the -O-H was not observed. The ${ }^{1} \mathrm{H}$ NMR spectrum of this polymer showed proton signals due to methacryloyl groups at 5.52-5.97 ppm. This result means that HBPS-MA with methacryloyl groups was prepared.

\section{Photo-Initiated Radical Polymerization of HBPS-MA}

The photo-initiated radical polymerization of HBPS-MA was performed in the film state. As shown in Figure 3, the reaction rapidly proceeded, and conversions reached to $54 \%$ at $14 \mathrm{~min}$. Furthermore, the photo-irradiated polymer film became insoluble in any organic solvents. On the other hand, it was observed that the rate of photochemical reaction of HBPS-MA was enhanced by the addition of low molecular weight monomer HEMA as diluent under the same irradiation conditions, and the conversions of the mixture of HBPS-MA (77 wt \%), HEMA (20 wt \%), and photo initiator (3 wt \%) reached to $58 \%$ at $14 \mathrm{~min}$. This means that the content of methacryloyl groups in the film was increased by the addition of HEMA and that the molecular motion in the film was increased by the addition of HEMA (low viscosity monomer). 


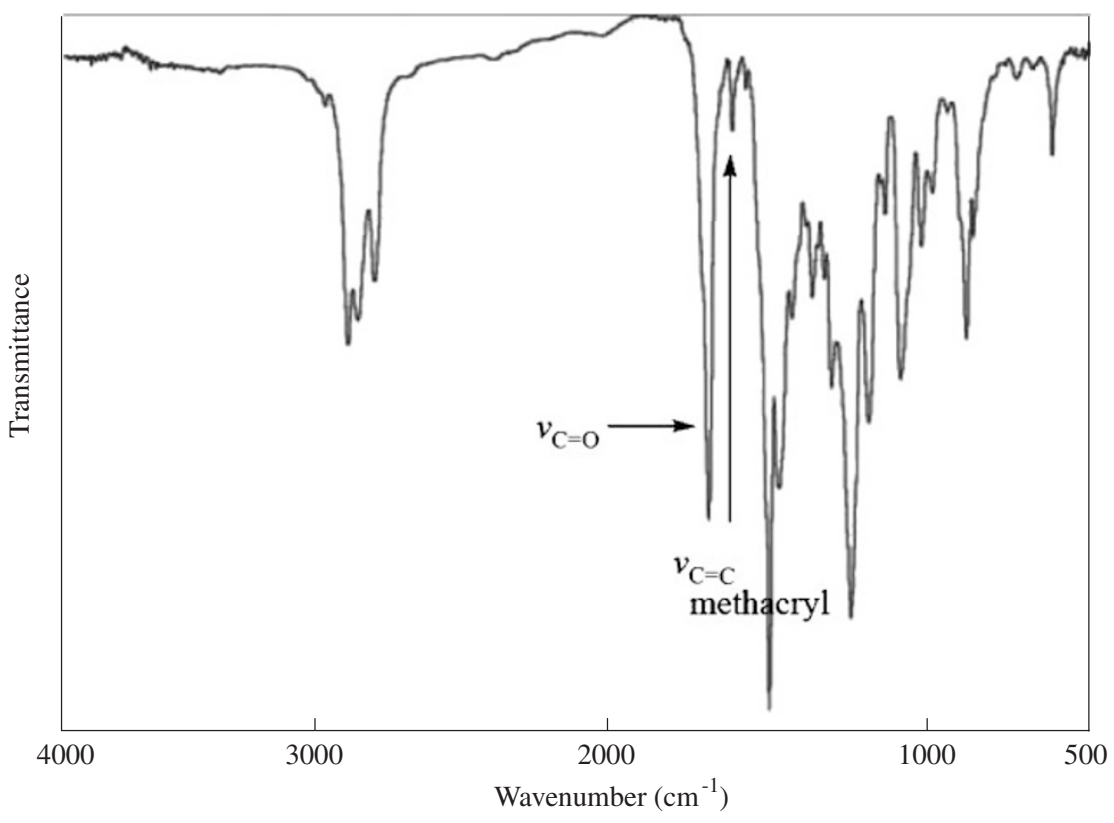

Figure 2. IR spectrum of HBPS-MA.

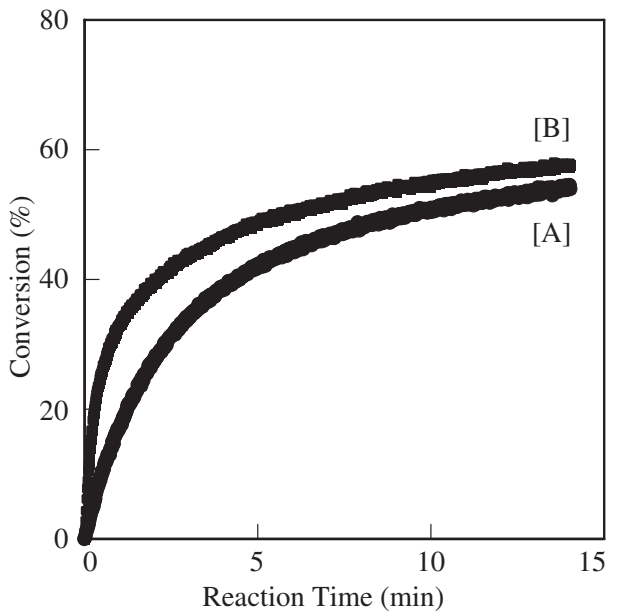

Figure 3. Time-conversion curve of the photoinitiated radical polymerization: [A] HBPS-MA (97 wt \%) and photo initiator (3wt \%), [B] HBPS-MA ( $77 \mathrm{wt} \%)$, HEMA (20 wt \%), and photo initiator (3wt \%).

\section{CONCLUSION}

From all these results, the following conclusions can be drawn. 1) HBPS was synthesized through the polyaddition of 1,4-BEOBM with TCA using TPPB as a catalyst. 2) The value of refractive index of the resulting HBPS was about 1.6. 3) HBPS-MA was synthesized through the reaction of HBPS with MAAH. 4) The obtained hyperbranched polymer showed high photo-reactivity.
Received: May 18, 2009

Accepted: June 26, 2009 Published: August 12, 2009

\section{REFERENCES}

1. "Synthesis and Application of Photosensitive Polymers," T. Nishikubo, Ed., CMC, Tokyo, 1979.

2. "Ultra-Violet and Electron Beam Curable Materials," Y. Tabata, Y. Takimoto, Y. Tominaga, H. Nakamoto, and T. Nishikubo, Eds., CMC, Tokyo, 1989.

3. S. R. Turner, B. I. Voit, and T. H. Mourey, Macromolecules, 26, 4617 (1993).

4. S. R. Turner, F. Walter, B. I. Voit, and T. H. Mourey, Macromolecules, 27, 1611 (1994).

5. Y. H. Kim and O. W. Webster, Macromolecules, 25, 5561 (1992).

6. W. Shi and B. Ranby, J. Appl. Polym. Sci., 59, 1937 (1996).

7. M. Okazaki, I. Washio, Y. Shibasaki, and M. Ueda, J. Am. Chem. Soc., 125, 8120 (2003).

8. R. Spindler and J. M. J. Fréchet, Macromolecules, 26, 4809 (1993).

9. J. Hao, M. Jikei, and M. Kakimoto, Macromolecules, 36, 3519 (2003).

10. S. Makita, H. Kudo, and T. Nishikubo, J. Polym. Sci., Part A: Polym. Chem., 42, 3697 (2004).

11. K. Maruyama, H. Kudo, T. Ikehara, N. Ito, and T. Nishikubo, J. Polym. Sci., Part A: Polym. Chem., 43, 4642 (2005).

12. K. Maruyama, H. Kudo, T. Ikehara, T. Nishikubo, I. Nishimura, A. Shishido, and T. Ikeda, Macromolecules, 40, 4895 (2007).

13. J. Liu, Y. Nakamura, Y. Shibasaki, S. Ando, and M. Ueda, Macromolecules, 40, 4614 (2007).

14. J. Liu, Y. Nakamura, Y. Shibasaki, S. Ando, and M. Ueda, Polym. J., 39, 543 (2007).

15. Y. Suzuki, J. Liu, Y. Nakamura, Y. Shibasaki, S. Ando, and M. Ueda, Polym. J., 40, 414 (2008).

16. H. Kudo, H. Inoue, T. Nishikubo, and T. Anada, Polym. J., 38, 289 (2006). 